\title{
Intraperitoneal clearance as a potential biomarker of cisplatin after intraperitoneal perioperative chemotherapy: a population pharmacokinetic study
}

\author{
B Royer ${ }^{* 1,2,3,4}$, E Kalbacher ${ }^{5}$, S Onteniente', V Jullien ${ }^{6}$, D Montange ${ }^{1,2}$, S Piedoux', A Thiery-Vuillemin ${ }^{5}$,

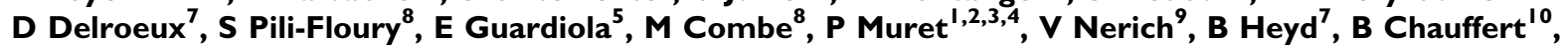 \\ J-P Kantelip' and X Pivot ${ }^{2,3,4,5}$
}

'CHU Besançon, Department of Pharmacology, Laboratoire de Pharmacologie Clinique - CHU Jean Minjoz - bvd Fleming, Besançon Cedex F25030, France; ${ }^{2}$ Inserm, UMR645, Besançon, France; ${ }^{3} \mathrm{CHU}$ Besançon, Clinical Investigation Center CIC-BT 506, Besançon, France; ${ }^{4}$ Franche-Comté University, IFR I33, Besançon, France; ${ }^{5} \mathrm{CHU}$ Besançon, Department of Oncology, Besançon, France; ${ }^{6}$ Department of Pharmacology, Paris Descartes University, Cochin-Saint-Vincent de Paul Hospital, Inserm, U663, Paris, France; ${ }^{7} \mathrm{CHU}$ Besançon, Department of Surgical Oncology, Besançon, France; ${ }^{8} \mathrm{CHU}$ Besançon, Department of Anesthesiology and Intensive Care Medicine, Besançon, France; ${ }^{9} \mathrm{CHU}$ Besançon, Department of Pharmacy, Besançon, France; ${ }^{10} \mathrm{CHU}$ Amiens, Department of Oncology, Amiens, France

BACKGROUND: Intraperitoneal (IP) perioperative chemotherapy with cisplatin is an interesting option in ovarian cancer treatment. A combination of cisplatin with IP epinephrine (already shown to improve IP and decrease systemic platinum (Pt) exposure) was evaluated using a population pharmacokinetic analysis.

METHODS: Data from 55 patients treated with cisplatin-based IP perioperative chemotherapy with $(n=26)$ or without $(n=29)$ epinephrine were analysed using NONMEM.

RESULTS: Epinephrine halves clearance between peritoneum and serum (IPCL) and increases the Pt central volume of distribution, IP exposure and penetration in tissue. IPCL has a better predictive value than any other parameter with respect to renal toxicity. CONCLUSION: This confirms that IPCL could be useful in assessing renal toxicity. As IPCL is also linked to tissue penetration and IP exposure, it may be proposed as biomarker. In addition to a Bayesian estimation, we propose a single-sample calculation-way to assess it. Prospective studies are needed to validate IPCL as a biomarker in this context.

British Journal of Cancer (2012) 1 06, 460-467. doi:I0.1038/bjc.201I.557 www.bjcancer.com

Published online 15 December 2011

(C) 2012 Cancer Research UK

Keywords: biomarker; cisplatin; epinephrine; intraperitoneal perioperative chemotherapy; population pharmacokinetics

Ovarian cancer is the main gynaecologic cause of death in Western countries, with $>75 \%$ of diagnosed cases presenting with regional or metastatic disease and a 5-year overall survival rate of approximately 30\% (Goodman et al, 2003). The American Cancer Society estimated that 21550 new cases of ovarian cancer were diagnosed and 14600 women died of the disease in 2009 in the United States (Jemal et al, 2009).

The standard treatment for advanced ovarian cancer combines optimal cytoreductive surgery (CRS), with intravenous carboplatin-paclitaxel chemotherapy (Aebi and Castiglione, 2008). However, intraperitoneal (IP) chemotherapy (IPC) may be proposed as an additional strategy aimed at achieving a high and more effective cytotoxic local concentration, while decreasing serum concentration (Markman and Walker, 2006). Three randomised phase-III clinical trials show a significant overall and/or progression-free survival advantage when IPC was used after CRS compared with

*Correspondence: Dr B Royer, E-mail: broyer@chu-besancon.fr Received 12 September 201 I; revised 17 November 2011; accepted 22 November 20 I ; published online 15 December $201 \mathrm{I}$ standard doses of intravenous chemotherapy (Alberts et al, 1996; Markman et al, 2001; Armstrong et al, 2006).

The difficulty of the drug to penetrate into the tumour and toxicities linked to high systemic concentrations impede the use of IPC as a 'routine' technique (Dedrick and Flessner, 1997; Rowan, 2009). Co-administration of epinephrine and cisplatin (CDDP) was proposed to solve these problems. Indeed, IP administration of this potent vasoconstrictor increased the penetration of platinum (Pt) derivatives into tumours (Duvillard et al, 1999; Favoulet et al, 2001; Chauffert et al, 2003). Such interesting properties led to phase-I studies to assess the feasibility of the IP epinephrinecisplatin combination in patients with advanced peritoneal carcinomatosis (Molucon-Chabrot et al, 2006; Guardiola et al, 2010). In particular, Guardiola et al (2010) showed that IP epinephrine decreases $\mathrm{Pt}$ concentrations in serum and is accompanied by a dramatic reduction in renal toxicity. The purpose of this study was to develop a population pharmacokinetic (POP PK) model of CDDP after perioperative IP administration with epinephrine aiming to assess its impact on the PK parameters and look at the phenomena occurring during this chemotherapy from a different angle. As the addition of IP epinephrine also reduces the rate of renal toxicity, a potential link between PK 
parameters and the clinical adverse effect of this drug should be investigated.

\section{MATERIALS AND METHODS}

\section{Clinical studies and patients}

The clinical and PK data used in the analysis were obtained from 55 patients treated with perioperative IPC (PIPC) with $(n=26)$ or without $(n=29)$ epinephrine (Guardiola et al, 2009, 2010). Eligible criterion was recurrent epithelial ovarian cancer, with progression at least 6 months after first-line i.v. chemotherapy based on Pt-containing regimen. Inclusion criteria included: histologically documented recurrent epithelial ovarian cancer confined to the peritoneal cavity (no extra-peritoneal disease), possibility of an optimal CRS aiming to remove all tumour nodules, age over 18, WHO performance status 0 or 1 , life expectancy $\geqslant 3$ months, and normal haematological, renal and hepatic functions. Owing to the anticipated cardiovascular effects of epinephrine, patients with a history of cardiac pathology were excluded. The study was conducted in compliance with the Declaration of Helsinki and signed informed consent forms were obtained from all patients.

\section{Treatments}

The treatment scheme included 4-8 cycles of i.v. induction chemotherapy with paclitaxel $\left(175 \mathrm{mg} \mathrm{m}^{-2}\right)$ and carboplatin (AUC 5), followed by optimal CRS during which PIPC with CDDP alone or the CDDP-epinephrine combination was administered. Perioperative IPC was administered as previously described (Royer et al, 2009; Guardiola et al, 2010). Epinephrine was then administered at $1(n=11), 2(n=12)$ and $3(n=3) \mathrm{mgl}^{-1}$ doses. The CDDP-containing baths lasted $1 \mathrm{~h}$, but for some patients $(n=11)$ treated with epinephrine, this duration was shortened by $15 \mathrm{~min}$. Indeed, after evaluating the IP Pt concentration, and as these concentrations were low and below the desired threshold (Royer et al, 2008), this decision (among others) was taken in an attempt to make this lengthy surgical procedure shorter. Three litres of normal saline, $2.2 \mathrm{Mm} \mathrm{Ca}^{2+}$ glucuronate, $1 \mathrm{gl}^{-1} \mathrm{Mg}^{2+}, 2 \mathrm{gl}^{-1} \mathrm{KCl}$ and $3 \mathrm{gl}^{-1} \mathrm{NaCl}$ were concomitantly intravenously administered for renal toxicity prevention.

\section{Pharmacokinetic study}

Peritoneal and blood sampling for PK analysis was as follows: peritoneal and blood samples were taken 1,30 and 59 min after the beginning of each of the two 1-h baths $(5,25$ and $44 \mathrm{~min}$ for the 45-min baths). Additional blood samples were collected 4, 6, 8, 16 and $24 \mathrm{~h}$ after the PIPC. The samples obtained $16 \mathrm{~h}$ after the beginning of chemotherapy were discarded for the last 11 patients because they were inconvenient and not informative (sampling time around 0300 hours). Blood and peritoneal samples were immediately centrifuged and separated in total and ultrafiltered (Uf) fractions, then frozen until analysis using a validated method based on flameless atomic absorption spectrophotometry using a Varian SpectrAA 220Z graphite furnace spectrometer with Zeeman effect (Varian, Mulgrave, Australia).

\section{Population pharmacokinetic analysis}

Concentration-time data were analysed using the non-linear mixed-effects approach with the NONMEM program version VI.2 software, with double precision (ICON Development Solutions, Elliott City, MD, USA) (Beal et al, 1989-2006). The first-order conditional method with the INTERACTION option was used. Both Uf and protein-bound $\mathrm{Pt}\left(\mathrm{Pt}_{\mathrm{B}}=\right.$ total $\left.\mathrm{Pt}-\mathrm{Uf} \mathrm{Pt}\right)$ were

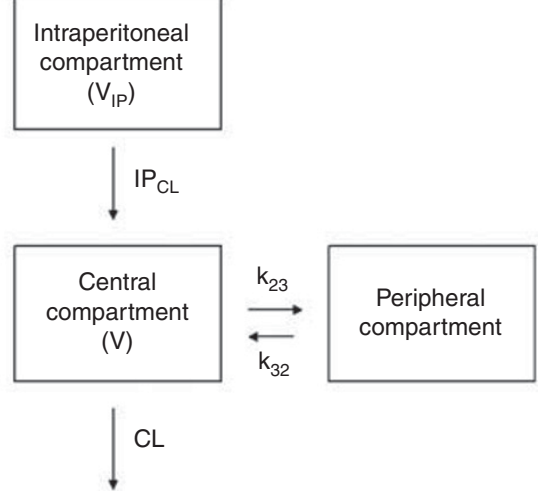

Figure I Scheme of the compartmental final model used for the modelling of both Uf and bound Pt. Administration of PIPC was performed in the IP compartment and Uf Pt was transferred to the central (serum) compartment following IP clearance IPCL. Ultrafiltered Pt can change between the central and peripheral compartments and be eliminated following central clearance $(\mathrm{CL})$. Ultrafiltered Pt can also bind to protein following a Michealis-Menten model $\left(K_{\max }, V_{M}\right)$ and thereafter be eliminated $\left(k_{\mathrm{B}}\right)$.

modelled simultaneously using the following (for details, see Supplementary data S1):

$$
\mathrm{Pt}_{\mathrm{B}}=\frac{V_{\mathrm{max}} \times \mathrm{Pt}_{\mathrm{Uf}}}{\mathrm{Pt}_{\mathrm{Uf}}+K_{\mathrm{M}}} \times \operatorname{Prot}
$$

This formula was used to model $\mathrm{Pt}_{\mathrm{B}}$ following the model of Urien and Lokiec (2004). The $\mathrm{Pt}_{\mathrm{B}}$ was modelled as an additional compartment and underwent first-order elimination from this compartment (Figure 1). This model was only applied to the serum concentrations because IP Pt binding was shown to be very low (Royer et al, 2005, 2008).

Identification of the best structural PK model was based on the objective function value and on the inspection of diagnostic graphs using the Perl speaks NONMEM (PsN) (Lindbom et al, 2005) and Xpose4 (Jonsson and Karlsson, 1999) toolkits. These programmes were also used to compute the extent of shrinkage in empirical Bayes estimates (eta-shrinkage) and individual predictions (epsilon-shrinkage). Computations were performed in the supercomputer facilities of the Mésocentre de calcul de Franche Comté.

Interindividual variability (IIV) was modelled exponentially. Several error models (i.e., additive, exponential or the combination of both error models) were investigated to describe the residual error. The covariates tested were age, actual body weight, height, body surface area (BSA) calculated according to the Du Bois and $\mathrm{Du}$ Bois formula (Du Bois and Du Bois, 1916), body mass index, serum creatinine, creatinine clearance (calculated according to the Cockroft-Gault equation (Cockroft and Gault, 1976)), IP total protein concentration (PRIP), serum total protein concentration (PROT), and presence of epinephrine (EPI - dichotomously coded because Pt plasma concentrations were similar regardless of the dose used (Guardiola et al, 2010)). Only covariates with a biologically plausible effect were tested. A covariate was retained in the population model if it produced a decrease in the objective function value of at least 3.84 points compared with the structural $\mathrm{PK}$ model, led to a reduction in the IIV of the associated PK parameter, and if a minimum increase in 7 was observed after its removal from the final model.

\section{Model evaluation}

The accuracy and robustness of the final population models were assessed by a (nonparametric) bootstrap method (Green and 
Duffull, 2003), visual predictive check and normalised prediction distribution errors (Brendel et al, 2006; Comets et al, 2008).

\section{Assessment of the epinephrine effect on Pt transfer}

To evaluate to what extent epinephrine reduces the amount of $\mathrm{Pt}$ transferring from peritoneum to bloodstream, we assessed such an individual transfer rate (RT) as follows (for details, see Supplementary data S1):

$$
\mathrm{RT}=\frac{\mathrm{AMT}_{\text {serum }}}{\mathrm{AMT}_{\mathrm{IP}}} \times 100
$$

(RT, percentage of $\mathrm{Pt}$, which passed from the peritoneum cavity to the bloodstream, $\mathrm{AMT}_{\text {serum, }}$ amount of $\mathrm{Pt}$ in serum, $\mathrm{AMT}_{\mathrm{IP}}$, amount of IP Pt).

\section{Pt penetration distance assessment}

An individual assessment of the distance at which the interstitial Pt concentration is $5 \%$ of that of the IP interface (named $3 x_{0}$ ), that is, an estimation of the Pt penetration, was determined following the studies of Dedrick and Flessner (1997) (for details, see Supplementary data $\mathrm{S} 1$ ):

$$
3 x_{0}=\frac{3 D \times \mathrm{BSA}}{\mathrm{IPCL}}
$$

With $3 x_{0}(\mu \mathrm{m})$, BSA $\left(\mu \mathrm{m}^{2}\right), D$ diffusivity $\left(\mu \mathrm{m}^{2} \mathrm{~min}^{-1}\right)$ (obtained from El-Kareh and Secomb (2004)) and IPCL is the individual clearance obtained with the Uf model $\left(\mu \mathrm{m}^{3} \mathrm{~min}^{-1}\right)$.

\section{Length of IP Pt exposure}

The time during which the IP concentration was over $10 \mathrm{mgl}^{-1}$ was calculated as follows using an equation derived from Kuti et al (2004):

$$
T=\ln \left(\frac{\mathrm{AMT}_{\mathrm{IP}}}{\mathrm{IPV} \times 10}\right) \times \frac{\mathrm{IPV}}{\mathrm{IPCL}}
$$

( $T$, time at which the $10 \mathrm{mgl}^{-1}$ concentration is reached in the peritoneum, $\mathrm{AMT}_{\mathrm{IP}}$ and IPCL as previously described, IPV, individual volume of distribution associated with the IP compartment).

\section{Assessment of predictive value of $\mathrm{PK}$ parameters regarding renal toxicity}

As postoperative renal toxicity remains the main adverse effect of PIPC (Guardiola et al, 2009; Pili-Floury et al, 2011), and as epinephrine dramatically reduces the occurrence of such toxicity, we assessed a potential link between several PK parameters (IPCL, $\mathrm{CL}, \mathrm{AUC}_{\text {serum }}$ and $\mathrm{AUC}_{\mathrm{IP}}$ ) and this toxicity. Renal toxicity was assessed according to RIFLE classification based on postoperative serum creatinine level changes from baseline (for details, see Supplementary data S1). Receiver operating characteristics curves were then calculated for each PK parameter. This allowed us to determine a threshold that was used to assess sensitivity, specificity, positive predictive value, negative predictive value and the odds ratio for each $\mathrm{PK}$ parameter.

\section{RESULTS}

\section{Patient population and structural PK model}

Clinical data of the patient population are summarised in Table 1. A total of 316 IP samples and 577 Uf plasma and 577 bound samples were used for the analysis. A three-compartment model with first-order elimination from the serum (central) compartment best fitted the data of all patients (Figure 1). The corresponding PK parameters were IPCL, volume of distribution associated with the IP compartment (IPV), clearance from the serum (central) compartment $(\mathrm{CL})$, volume of distribution associated with the serum central compartment (V), Michaelis-Menten constants used to model covalent binding to protein $\left(V_{\max }\right.$ and $K_{\mathrm{M}}$ ), elimination constant rate of $\mathrm{Pt}_{\mathrm{B}}\left(k_{\mathrm{B}}\right)$, and the rate constants between serum central and peripheral compartments $\left(k_{23}\right.$ and $\left.k_{32}\right)$ (Table 2). Interindividual variability on $k_{23}, k_{32}, K_{\mathrm{M}}$ and $k_{\mathrm{B}}$ could not be estimated. A correlation between $\mathrm{V}$ and $V_{\max }$ was observed and estimated. The error model includes both proportional and additive models, but the latter was only applied to IP concentrations.

\section{Covariates}

Only epinephrine led to a significant decrease in IIV. Epinephrine decreased the objective functional value and IIV for both IPCL and $\mathrm{V}$. The administration of epinephrine led to an IPCL decrease in $53.1 \%$ and an increase in $\mathrm{V}$ of $80.5 \%$. Associated variability was reduced by 48.9 and $53.4 \%$.

\section{Model evaluation}

The goodness-of-fit plots for all samples of the final model are shown in Figures $2 \mathrm{~A}-\mathrm{D}$. The goodness was confirmed for each studied compartment (Supplementary Figures S2 - supplementary material). The bootstrapped mean and $95 \mathrm{CI}$ of the parameter estimates are summarised in Table 2.

The figures corresponding to the posterior visual predictive check and the normalised prediction distribution errors evaluation confirm the satisfactory predictability of the final population PK models (Supplementary material - Supplementary Figures S3A and S3B, respectively). In particular, the 15-min reduction of PIPC was correctly modelled (see Supplementary Figure S3A) and thus

Table I Summary of baseline characteristics of patients who underwent IP peroperative chemotherapy with CDDP combined or not with epinephrine

\begin{tabular}{lccc}
\hline & IP CDDP $(n=29)$ & IP CDDP-epinephrine association $(n=26)$ & All patients $(n=55)$ \\
\hline Age (years) & $58.2(25.5-75.0)$ & $59.1(26.6-70.8)$ & $58.3(25.5-75.0)$ \\
Actual weight $(\mathrm{kg})$ & $57(49-84)$ & $61(49-85)$ & $60.5(49-85)$ \\
Lean body mass $(\mathrm{kg})$ & $43.0(38.4-56.2)$ & $43.8(36.6-51.7)$ & $163.6(36.6-56.2)$ \\
Height $(\mathrm{cm})$ & $163(150-176)$ & $23.4(20.2-31.2)$ & $161.5(150-178)$ \\
Body mass index $\left(\mathrm{kg} \mathrm{m}^{-2}\right)$ & $23.6(17.9-28.5)$ & $1.63(1.42-1.92)$ & $23.4(17.9-31.2)$ \\
Body surface area $\left(\mathrm{m}^{2}\right)^{\mathrm{a}}$ & $1.26(1.48-2.01)$ & $44.5(36.6-51.7)$ & $1.63(1.42-2.01)$ \\
Lean body mass $\left(\mathrm{kg}^{\mathrm{b}}\right.$ & $44.7(38.4-56.2)$ & $62.5(48-88)$ & $44.7(36.6-56.2)$ \\
Serum creatinine $\left(\mu \mathrm{moll}^{-1}\right)$ & $57.1(32-79)$ & $80.0(58.2-133.2)$ & $58.0(32-88)$ \\
Creatinine clearance $\left(\mathrm{ml} \mathrm{min}^{-1}\right)^{c}$ & $97.5(72.6-182.8)$ & $36.5(22-56)$ & $94.0(58.2-182.8)$ \\
Total protein concentration in serum $\left(\mathrm{gl}^{-1}\right)$ & $31.0(16-42)$ & $34.0(16-56)$ \\
\hline
\end{tabular}

Abbreviations: $\mathrm{CDDP}=$ cisplatin; $\mathrm{IP}=$ intraperitoneal. ${ }^{\mathrm{a}}$ Calculated according to the Dubois and Dubois formula. ${ }^{\mathrm{b}} \mathrm{Calculated}$ according to the James formula. ${ }^{\mathrm{c}}$ Estimated with the Cockcroft and Gault formula. Data are presented as median (range). 
Table 2 Population pharmacokinetics parameters of Pt estimated from the final model and bootstrap validation (500 resamplings)

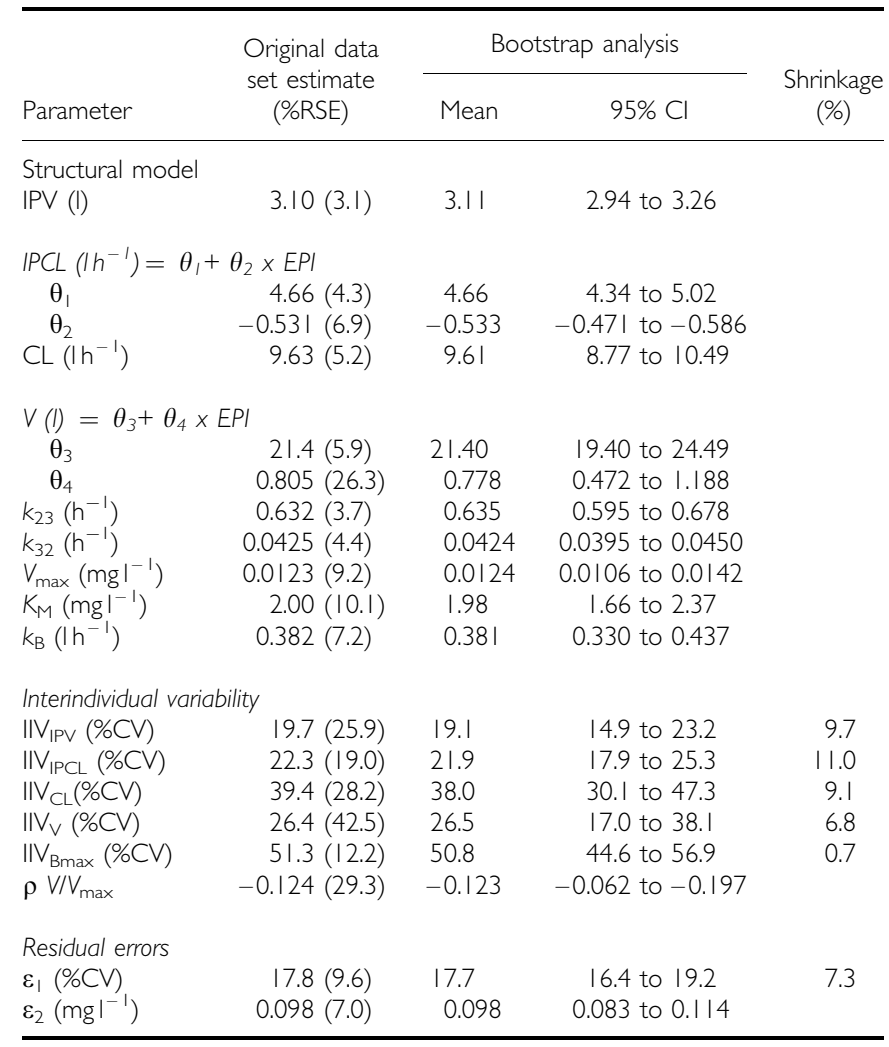

Abbreviations: $\theta=$ value of the parameter associated with the equation of the covariate; $\varepsilon_{1}=$ exponential part of the residual error; $\varepsilon_{2}=$ additive part of the residual error; $\mathrm{Cl}=$ confidence interval; $\% \mathrm{CV}=$ percentage of coefficient of variation; $\mathrm{CL}=$ clearance associated with the serum (central) compartment; $\mathbb{P C L}=\mathbb{P}$ clearance; IIV = interindividual variability; $\mathrm{Pt}=$ platinum; \%RSE = relative standard error; $V$ and IPV = volume of distribution associated with the serum central and IP compartments; $V_{\max }$ and $K M=$ the Michaelis-Menten constants used to model covalent binding to protein; $k_{\mathrm{B}}=$ the elimination constant rate of Pt-bound $\mathrm{Pt}$ to protein; $k_{23}, k_{32}=$ rate constants between central and peripheral compartments.

enables us to analyse these patients together with those treated with the 1 -h baths.

\section{Impact of epinephrine effect on $\mathrm{Pt}$}

The decrease in IPCL because of epinephrine reduced the rate of transfer of Pt from peritoneum to bloodstream by $40.2 \%$ (mean individual, $P<10^{-4}$ ) (Figure $3 \mathrm{~A}$ ). This was accompanied by an increase in the length of time during which IP Pt concentration was higher than $10 \mathrm{mgl}^{-1}$ (a concentration associated with the cytotoxicity of a resistant cell line (Royer et al, 2005; Facy et al, 2011)). After epinephrine administration, this duration more than doubled $\left(25.1 \pm 6.8 \mathrm{~min}\right.$ vs $53.9 \pm 13.5 \mathrm{~min}, P<10^{-4}$ ) (Figure $3 \mathrm{C}$ ). Interestingly, the addition of epinephrine in the peritoneal bath also led to an increase in the calculated Pt penetration in interstitial tissue. The mean Pt penetration was $992 \pm 219 \mu \mathrm{m}$ without epinephrine vs $2100 \pm 473 \mu \mathrm{m}$ with epinephrine $\left(P<10^{-4}\right)$ (Figure 3B).

\section{Selection of IPCL as the best marker of toxicity}

Of the 29 patients who did not receive epinephrine, 28 were able to undergo renal toxicity assessment (Supplementary data S1). Of these, 14 underwent high clinical toxicity (IF) while this toxicity was lower in the 14 other patients. The 26 patients treated with epinephrine did not develop renal injury or failure.

Receiver operating characteristics curves indicate that IPCL, $\mathrm{AUC}_{\mathrm{IP}}$ and $\mathrm{AUC}_{\text {serum }}$, but not $\mathrm{CL}$ are able to discriminate patients with a potential risk of renal toxicity (Supplementary data - Supplementary Figure S4). For these three PK parameters, predictive values (sensitivity, specificity, positive predictive value, negative predictive value and odds ratio) show that IPCL seems to be the best parameter for predicting potential CDDP toxicity (Table 3 ). To reduce the number of samples and simplify the sampling schedule, the Bayesian estimation of IPCL was assessed with only the last IP sample of each bath. These estimations led to satisfactory values of IPCL with a higher positive predictive value than IPCL obtained with all samples, but a lower negative predictive value (Table 3 and Supplementary data - Supplementary Figure S4). However, a biomarker must be easily accessible in order to be effective. We therefore aimed to calculate IPCL directly using the Uf IP concentration of Pt with the following formula:

$$
\mathrm{IPCL}=-\frac{V}{t} \operatorname{Ln}\left(\frac{C(t) \cdot V}{D}\right)
$$

$(V(\mathrm{l})$, volume in which $\mathrm{Pt}$ is administered with the dose $D(\mathrm{mg})$; $C(t)$, concentration of Uf IP Pt measured at the time $t)$.

Taking the last values of Pt of each bath, the calculated IPCL values give a lower AUC for receiver operating characteristics curve (Supplementary data - Supplementary Figure S4), but provide good predictive values that are similar to those observed with the Bayesian estimation or with all the samples (Table 3).

\section{DISCUSSION}

Population pharmacokinetic studies give another view of the pharmacokinetic phenomena taking place during this chemotherapy. We described the effect of epinephrine on $\mathrm{V}$ and on the clearance between IP and serum. The considerable increase in V after epinephrine administration was somewhat surprising. The role of epinephrine in the increase in V may be explained by a $\beta 1$-adrenergicmediated myocardial stimulation (positive inotropic and chronotropic actions) and a $\beta 2$-mediated peripheral vasodilatation (decrease in peripheral resistance). Consequently, the blood flow distribution in tissues increases together with the rate and extent of $\mathrm{Pt}$ transfer outside the capillaries, resulting in lower total Pt serum concentration (Fagiolino et al, 2006). Of note, an increase in V was also observed when epinephrine was used in combination with local anaesthetics after perineural administration (Tucker and Mather, 1979) meaning that this effect is probably not related to the mode of administration, nor to the combined drug. The decrease in IPCL is thought to be partly due to a reduction in splanchnic blood flow ( $\alpha 1$-adrenergic vasoconstriction of the peritoneal vessels). The combination of the increase in $\mathrm{V}$ and the decrease in IPCL may explain the decrease in concentrations observed after epinephrine administration (Guardiola et al, 2010).

Interestingly, the POP PK study provides access to individual IPCL. This enabled us to assess the individual Pt penetration in peritoneal tissue. The effect of epinephrine was clear-cut (Figure 3): the mean Pt penetration more than doubled. Although these values of penetration were obtained with a theoretical model, they were in the same range as those observed in animal models (Los et al, 1989, 1990; Duvillard et al, 1999; Favoulet et al, 2001; Chauffert et al, 2003; Esquis et al, 2006) and those obtained after hyperthermia in humans (van de Vaart et al, 1998). However, in animal models, epinephrine was shown to be more effective than hyperthermia in enhancing intratumoural concentration of $\mathrm{Pt}$ while decreasing its peripheral concentration and extra-peritoneal tissue penetration (Facy et al, 2011). Moreover, epinephrine increases the 

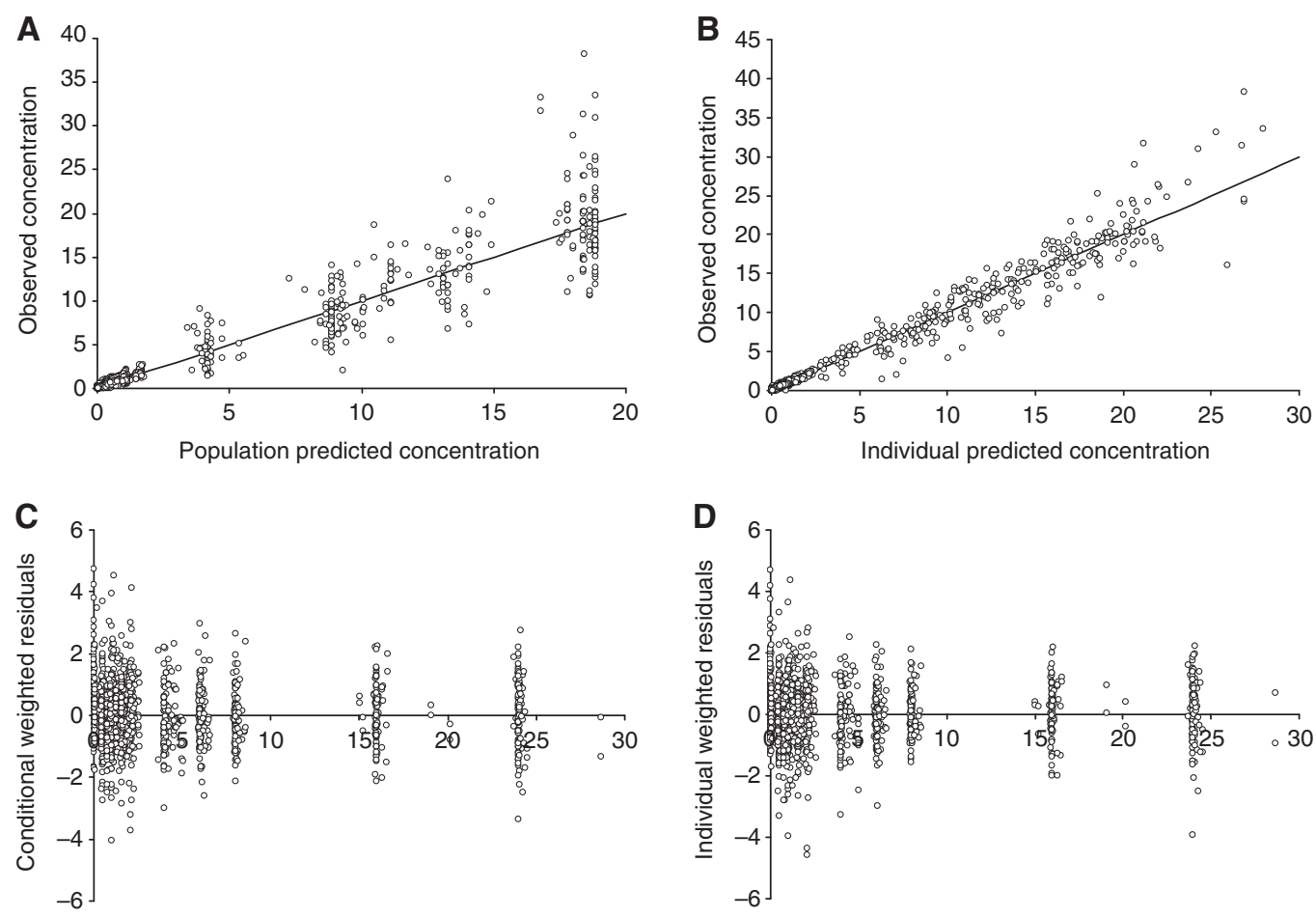

Time (h)

Time (h)

Figure 2 Scatterplots allowing us to assess the goodness-of-fit for the final models. Graphs represent model-Predicted (PRED) (A) and Individual Predicted (B - shrinkage $\leqslant 11.0 \%)$ concentrations plotted vs Observed concentrations, as well as Conditional (C) and Individual (D) Weighted Residuals vs Time. These concentrations were observed for the concentrations obtained IP, in serum and for bound Pt. The scatterplots for each compartment are displayed in Supplementary Figure S2 of the Supplementary data.
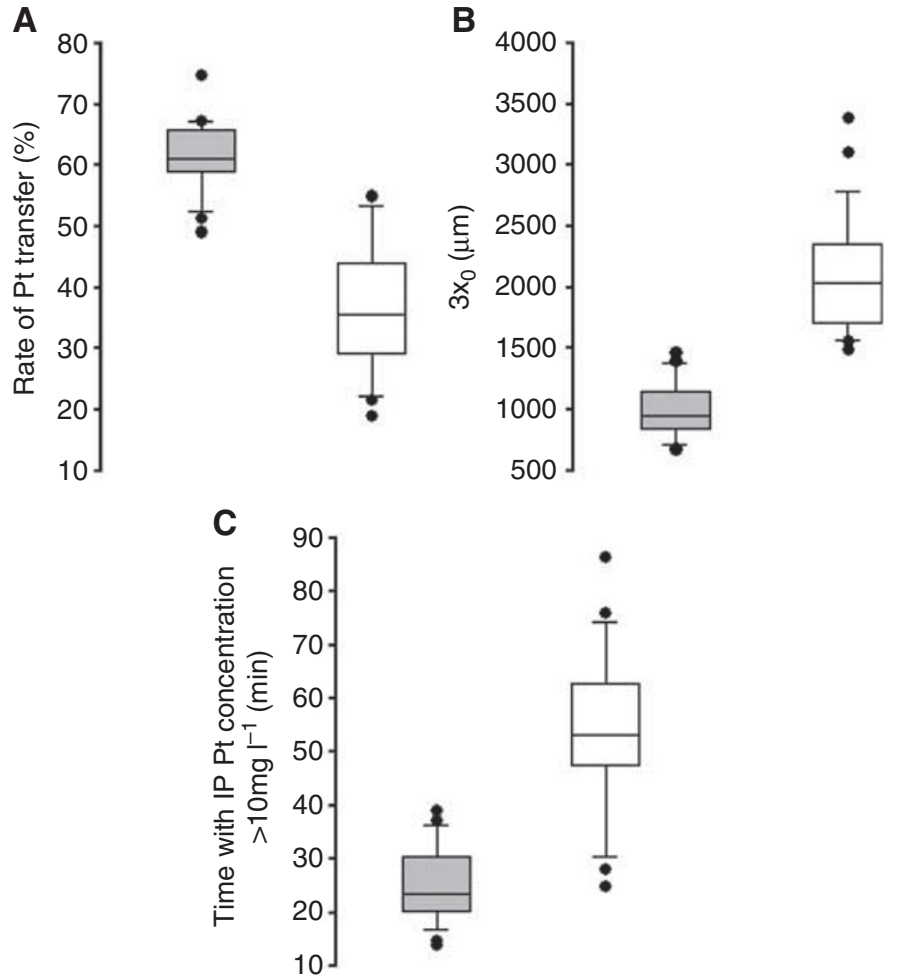

Figure 3 Effect of epinephrine on Pt behaviour during PIPC. (A) The effect of epinephrine on individual rate of transfer of Uf Pt from peritoneum to bloodstream. (B) Assessment of the effect of epinephrine on the individual Pt penetration. $3 x_{0}(\mu \mathrm{m})$ is the distance in peritoneal tissue at which the concentration difference between tissue and blood perfusing this tissue decreased to $5 \%$ of its maximal value. (C) Time during which the IP Pt concentration is over $10 \mathrm{mgI}^{-1}$. The data were obtained for patients treated with cisplatin with (white box) or without (grey box) epinephrine. $\ddagger$ means $P<10^{-4}$ ( $t$-test) as compared with values observed without epinephrine. 
Table 3 Predictive values of different PK parameters with respect to renal toxicities

\begin{tabular}{|c|c|c|c|c|c|c|c|}
\hline & AUC of ROC curve & Threshold & Sensitivity & Specificity & Positive predictive value & Negative predictive value & OR $(95 \% \mathrm{Cl})$ \\
\hline IPCL & 0.909 & 4.1 & 0.929 & 0.825 & 0.650 & 0.971 & $61.3(9.5-395.0)$ \\
\hline$C L$ & 0.514 & & NA & NA & NA & NA & NA \\
\hline$A \cup C_{\mathbb{P}}$ & 0.855 & 19.6 & 0.714 & 0.800 & 0.556 & 0.889 & $10.0(2.6-38.1)$ \\
\hline$A \cup C_{\text {serum }}$ & 0.854 & 4.5 & 0.857 & 0.725 & 0.522 & 0.935 & $15.8(3.5-72.3)$ \\
\hline $\mathrm{IPC} \mathrm{L}_{\text {Bayes }}$ & 0.923 & 4.5 & 0.786 & 0.872 & 0.688 & 0.919 & $24.9(5.6-111.4)$ \\
\hline$I P C L_{\text {calc }}$ & 0.892 & 3.2 & 0.857 & 0.821 & 0.632 & 0.941 & $27.4(5.7-132.2)$ \\
\hline
\end{tabular}

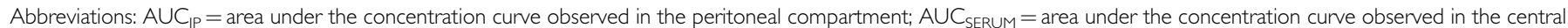

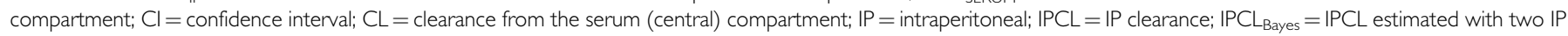

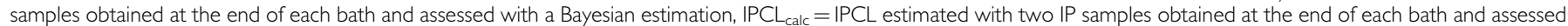

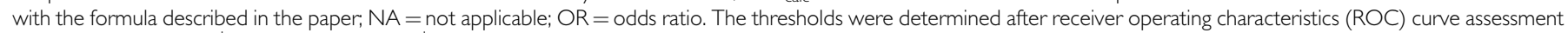
and their units are $\mathrm{Ih}^{-1}$ for IPCL and $\mathrm{mghl}^{-1}$ for both AUCs. Predictive values of $\mathrm{CL}$ were not evaluated because of too bad ROC evaluation.

time during which the concentration is above $10 \mathrm{mgl}^{-1}$. These effects are interesting as, to be clinically relevant, the high and sustained IP Pt level must result in significant Pt accumulation in tumour nodules (Rao et al, 2007; Van der Speeten et al, 2009).

The administration of epinephrine led to the suppression of the clinically relevant renal toxicity previously observed in around half of the patients (Supplementary data S1). As we observed that epinephrine administration led to a great difference in both creatinine ratio and serum Pt concentrations (Guardiola et al, 2010), we assumed that, thanks to the POP PK study providing access to individual PK parameters, this could help us to determine a PK parameter linked to renal toxicity. IPCL was the best PK parameter for predicting renal toxicity, showing the best predictive values. This is unsurprising, as this parameter pharmacokinetically drives both the IP and serum AUC. Interestingly, IPCL may also be used to compute pharmacodynamic parameters. However, as we could not directly link this parameter to efficacy, further prospective studies are needed to correlate this parameter with efficacy. This parameter could thus be used to assess both toxicity and possibly efficacy of cisplatin perioperative IP administration. Indeed, there are a few biomarkers in the field of IPC. Although CA125 was proposed as a predictor of progression-free and overall survival in ovarian cancer patients before IPC (Juretzka et al, 2007), its interest is controversial (Juretzka et al, 2007; Richardson et al, 2008; Richard et al, 2010). Moreover, as there is neither a marker of toxicity nor of efficacy for cisplatin-based IPC, IPCL could be useful in this context. However, further studies, with more homogeneous patients than those we studied, are needed to assess this parameter prospectively in terms of toxicity and efficacy. This is the condition required to consider IPCL as a biomarker of cisplatin when after PIPC.

A biomarker needs to be easily assessable in biological fluids of patients. However, in this study, IPCL was obtained after an intensive sampling schedule and a POP PK analysis, making access to this parameter difficult. We first aimed to reduce the number of samples to the last IP sample of each bath. Using the final model, the Bayesian estimation of IPCL with only these two samples was satisfactory. Second, to make the IPCL assessment possible without the POP PK approach, we attempted to calculate it considering the following approximations: $\mathrm{V}$ was set to the volume of chemotherapy. This approximation was possible because this parameter displays low variability when estimated with POP PK (Royer et al, 2009; Cotte et al, 2011), and both low IP protein concentration and low protein binding leads to this volume being close to V. Thus, considering both the administered dose and volume (easily available with an open procedure), the IP Uf concentration obtained just before the end of IPC can be used to calculate the IPCL directly using the equation previously described. Using this method, we obtained IPCL predictive values similar to those obtained using NONMEM (with the full model or the Bayesian estimation), which makes this parameter easily available even without POP PK modelling (with or without epinephrine). However, the approximations used to calculate this parameter may weaken its predictive value. For instance, the individual estimation of IPCL using the POP PK approach indirectly takes into account parameters that dictate the Pt transfer, such as the permeability and the effective contact area (Supplementary data S1). Direct calculation of IPCL with the proposed formula does not. In the event of huge preoperative malignant ascites, POP PK estimation of IPCL may be more realistic than the calculated approach. The estimation of the surface of the contact area by BSA for the interstitial penetration assessment may also be biased. For these reasons, it seems very important to assess the predictive values of these parameters in prospective studies in which these potential biases should be detected and evaluated.

In conclusion, the present POP PK analysis aimed to propose a potential biomarker of cisplatin after PIPC. Two characteristics of this study make this possible. First, the POP PK approach provides access to individual PK parameters. Second, the administration of epinephrine led to a dramatic reduction in renal toxicity. Taken together, these approaches led to a correlation study, which showed that the IPCL appears the best parameter linked to toxicity, and that this parameter could potentially be related to efficacy. Given that the POP PK approach is not widely available, we propose a more simple approach to assess this parameter. Although the assessment of IPCL with only one sample using the proposed equation is not as precise as the Bayesian estimation, this approach may be universally adopted with a view to a prospective study to confirm this approach and determine an essential threshold for patient follow-up.

\section{ACKNOWLEDGEMENTS}

We are grateful to the technicians of the Pharmacology Department for their expert Pt determination and Ms F Sheppard (Inserm Clinical Investigation Center, Besançon) for her editorial assistance. This work was partly supported by the 'Ligue contre le Cancer, Comité du Doubs'.

\section{Conflict of interest}

The authors declare no conflict of interest.

Supplementary Information accompanies the paper on British Journal of Cancer website (http://www.nature.com/bjc) 


\section{REFERENCES}

Aebi S, Castiglione M (2008) Epithelial ovarian carcinoma: ESMO clinical recommendations for diagnosis, treatment and follow-up. Ann Oncol 19(Suppl 2): ii14-ii16

Alberts DS, Liu PY, Hannigan EV, O'Toole R, Williams SD, Young JA, Franklin EW, Clarke-Pearson DL, Malviya VK, DuBeshter B (1996) Intraperitoneal cisplatin plus intravenous cyclophosphamide versus intravenous cisplatin plus intravenous cyclophosphamide for stage III ovarian cancer. $N$ Engl J Med 335: 1950-1955

Armstrong DK, Bundy B, Wenzel L, Huang HQ, Baergen R, Lele S, Copeland LJ, Walker JL, Burger RA (2006) Intraperitoneal cisplatin and paclitaxel in ovarian cancer. $N$ Engl J Med 354: 34-43

Beal SL, Sheiner LB, Boeckmann AJ NONMEM Users Guides. Ellicott City MD 1989-2006

Brendel K, Comets E, Laffont C, Laveille C, Mentre F (2006) Metrics for external model evaluation with an application to the population pharmacokinetics of gliclazide. Pharm Res 23: 2036-2049

Chauffert B, Favoulet P, Polycarpe E, Duvillard C, Beltramo JL, Bichat F, Rat P, Genne P, Benoit L (2003) Rationale supporting the use of vasoconstrictors for intraperitoneal chemotherapy with platinum derivatives. Surg Oncol Clin N Am 12: $835-848$

Cockroft DW, Gault MH (1976) Prediction of creatinine clearance from serum creatinine. Nephron 16: $31-41$

Comets E, Brendel K, Mentre F (2008) Computing normalised prediction distribution errors to evaluate nonlinear mixed-effect models: the npde add-on package for R. Comput Methods Programs Biomed 90: $154-166$

Cotte E, Colomban O, Guitton J, Tranchand B, Bakrin N, Gilly FN, Glehen O, Tod M (2011) Population pharmacokinetics and pharmacodynamics of cisplatinum during hyperthermic intraperitoneal chemotherapy using a closed abdominal procedure. J Clin Pharmacol 51(1): 9-18

Dedrick RL, Flessner MF (1997) Pharmacokinetic problems in peritoneal drug administration: tissue penetration and surface exposure. J Natl Cancer Inst 89: 480-487

$\mathrm{Du}$ Bois D, Du Bois EF (1916) A formula to estimate the approximate surface area if height and weight be known. Arch Intern Med 17: 863-871

Duvillard C, Benoit L, Moretto P, Beltramo JL, Brunet-Lecomte P, Correia M, Sergent C, Chauffert B (1999) Epinephrine enhances penetration and anti-cancer activity of local cisplatin on rat sub-cutaneous and peritoneal tumors. Int J Cancer 81: 779-784

El-Kareh AW, Secomb TW (2004) A theoretical model for intraperitoneal delivery of cisplatin and the effect of hyperthermia on drug penetration distance. Neoplasia 6: $117-127$

Esquis P, Consolo D, Magnin G, Pointaire P, Moretto P, Ynsa MD, Beltramo JL, Drogoul C, Simonet M, Benoit L, Rat P, Chauffert B (2006) High intra-abdominal pressure enhances the penetration and antitumor effect of intraperitoneal cisplatin on experimental peritoneal carcinomatosis. Ann Surg 244: $106-112$

Facy O, Radais F, Ladoire S, Delroeux D, Tixier H, Ghiringhelli F, Rat P, Chauffert B, Ortega-Deballon P (2011) Comparison of hyperthermia and adrenaline to enhance the intratumoral accumulation of cisplatin in a murine model of peritoneal carcinomatosis. J Exp Clin Cancer Res 30: 4

Fagiolino P, Eiraldi R, Vazquez M (2006) The influence of cardiovascular physiology on dose/pharmacokinetic and pharmacokinetic/pharmacodynamic relationships. Clin Pharmacokinet 45: 433-448

Favoulet P, Magnin G, Guilland JC, Beltramo JL, Osmak L, Benoit L, Rat P, Douvier S, Duvillard C, Chauffert B (2001) Pre-clinical study of the epinephrine-cisplatin association for the treatment of intraperitoneal carcinomatosis. Eur J Surg Oncol 27: 59-64

Goodman MT, Correa CN, Tung KH, Roffers SD, Cheng Wu X, Young Jr JL, Wilkens LR, Carney ME, Howe HL (2003) Stage at diagnosis of ovarian cancer in the United States, 1992-1997. Cancer 97: 2648-2659

Green B, Duffull SB (2003) Prospective evaluation of a D-optimal designed population pharmacokinetic study. J Pharmacokinet Pharmacodyn 30: $145-161$

Guardiola E, Chauffert B, Delroeux D, Royer B, Heyd B, Combe M, Benoit L, Causeret S, Demarchi M, Magnin G, Mayer F, Tixier H, Pivot X (2010) Intraoperative chemotherapy with cisplatin and epinephrine after cytoreductive surgery in patients with recurrent ovarian cancer: a phase I study. Anticancer Drugs 21: $320-325$

Guardiola E, Delroeux D, Heyd B, Combe M, Lorgis V, Demarchi M, Stein U, Royer B, Chauffert B, Pivot X (2009) Intra-operative intraperitoneal chemotherapy with cisplatin in patients with peritoneal carcinomatosis of ovarian cancer. World J Surg Oncol 7: 14
Jemal A, Siegel R, Ward E, Hao Y, Xu J, Thun MJ (2009) Cancer statistics, 2009. CA Cancer J Clin 59: 225-249

Jonsson EN, Karlsson MO (1999) Xpose-an S-PLUS based population pharmacokinetic/pharmacodynamic model building aid for NONMEM. Comput Methods Programs Biomed 58: 51-64

Juretzka MM, Barakat RR, Chi DS, Iasonos A, Dupont J, Abu-Rustum NR, Poynor EA, Aghajanian C, Spriggs D, Hensley ML, Sabbatini P (2007) CA125 level as a predictor of progression-free survival and overal survival in ovarian cancer patients with surgically defined disease status prior to the initiation of intraperitoneal consolidation therapy. Gynecol Oncol 104: $176-180$

Kuti JL, Nightingale CH, Nicolau DP (2004) Optimizing pharmacodynamic target attainment using the MYSTIC antibiogram: data collected in North America in 2002. Antimicrob Agents Chemother 48: 2464-2470

Lindbom L, Pihlgren P, Jonsson EN (2005) PsN-Toolkit-a collection of computer intensive statistical methods for non-linear mixed effect modeling using NONMEM. Comput Methods Programs Biomed 79: $241-257$

Los G, Mutsaers PH, Lenglet WJ, Baldew GS, McVie JG (1990) Platinum distribution in intraperitoneal tumors after intraperitoneal cisplatin treatment. Cancer Chemother Pharmacol 25: 389-394

Los G, Mutsaers PH, van der Vijgh WJ, Baldew GS, de Graaf PW, McVie JG (1989) Direct diffusion of cis-diamminedichloroplatinum(II) in intraperitoneal rat tumors after intraperitoneal chemotherapy: a comparison with systemic chemotherapy. Cancer Res 49: 3380-3384

Markman M, Bundy BN, Alberts DS, Fowler JM, Clark-Pearson DL, Carson LF, Wadler S, Sickel J (2001) Phase III trial of standard-dose intravenous cisplatin plus paclitaxel versus moderately high-dose carboplatin followed by intravenous paclitaxel and intraperitoneal cisplatin in small-volume stage III ovarian carcinoma: an intergroup study of the Gynecologic Oncology Group, Southwestern Oncology Group, and Eastern Cooperative Oncology Group. J Clin Oncol 19: $1001-1007$

Markman M, Walker JL (2006) Intraperitoneal chemotherapy of ovarian cancer: a review, with a focus on practical aspects of treatment. J Clin Oncol 24: $988-994$

Molucon-Chabrot C, Isambert N, Benoit L, Zanetta S, Fraisse J, Guilland JC Royer B, Monin-Baroille P, Flesch M, Fargeot P, Coudert B, Mayer F, Fumoleau P, Chauffert B (2006) Feasibility of using intraperitoneal epinephrine and cisplatin in patients with advanced peritoneal carcinomatosis. Anticancer Drugs 17: 1211 - 1217

Pili-Floury S, Royer B, Bartholin F, Crumiere N, Combe M, Chalopin JM, Pivot X, Heyd B, Chauffert B, Samain E (2011) Protective effect of intraperitoneal epinephrine on postoperative renal function after cisplatinbased intra-peritoneal intra-operative chemotherapy. Eur J Obstet Gynecol Reprod Biol 156: 199-203

Rao G, Crispens M, Rothenberg ML (2007) Intraperitoneal chemotherapy for ovarian cancer: overview and perspective. J Clin Oncol 25: $2867-2872$

Richard SD, Sukumvanich P, Lesnock JL, McBee WC, Beriwal S, Edwards RP, Zorn KK, Krivak TC (2010) Intraperitoneal catheter leads to prolongation of the time to normalization of serum CA125 levels. Int $J$ Gynecol Cancer 20: $932-935$

Richardson DL, Seamon LG, Carlson MJ, O'Malley DM, Fowler JM, Copeland LJ, Cohn DE (2008) CA125 decline in ovarian cancer patients treated with intravenous versus intraperitoneal platinum-based chemotherapy. Gynecol Oncol 111: 233-236

Rowan K (2009) Intraperitoneal therapy for ovarian cancer: why has it not become standard? J Natl Cancer Inst 101: 775-777

Royer B, Delroeux D, Guardiola E, Combe M, Hoizey G, Montange D, Kantelip JP, Chauffert B, Heyd B, Pivot X (2008) Improvement in intraperitoneal intraoperative cisplatin exposure based on pharmacokinetic analysis in patients with ovarian cancer. Cancer Chemother Pharmacol 61: 415-421

Royer B, Guardiola E, Polycarpe E, Hoizey G, Delroeux D, Combe M, Chaigneau L, Samain E, Chauffert B, Heyd B, Kantelip JP, Pivot X (2005) Serum and intraperitoneal pharmacokinetics of cisplatin within intraoperative intraperitoneal chemotherapy: influence of protein binding. Anticancer Drugs 16: 1009 - 1016

Royer B, Jullien V, Guardiola E, Heyd B, Chauffert B, Kantelip JP, Pivot X (2009) Population pharmacokinetics and dosing recommendations for cisplatin during intraperitoneal peroperative administration: development of a limited sampling strategy for toxicity risk assessment. Clin Pharmacokinet 48: $169-180$ 
Tucker GT, Mather LE (1979) Clinical pharmacokinetics of local anaesthetics. Clin Pharmacokinet 4: 241-278

Urien S, Lokiec F (2004) Population pharmacokinetics of total and unbound plasma cisplatin in adult patients. Br J Clin Pharmacol 57: $756-763$

van de Vaart PJ, van der Vange N, Zoetmulder FA, van Goethem AR, van Tellingen $\mathrm{O}$, ten Bokkel Huinink WW, Beijnen JH, Bartelink H,
Begg AC (1998) Intraperitoneal cisplatin with regional hyperthermia in advanced ovarian cancer: pharmacokinetics and cisplatin-DNA adduct formation in patients and ovarian cancer cell lines. Eur J Cancer 34: $148-154$

Van der Speeten K, Stuart OA, Sugarbaker PH (2009) Pharmacokinetics and pharmacodynamics of perioperative cancer chemotherapy in peritoneal surface malignancy. Cancer J 15: 216-224

This work is published under the standard license to publish agreement. After 12 months the work will become freely available and the license terms will switch to a Creative Commons Attribution-NonCommercial-Share Alike 3.0 Unported License. 